\title{
Demands, Resources and the Three Dimensions of Flow at Work. A Study among Professional Nurses
}

\author{
Lara Colombo, Margherita Zito \\ Department of Psychology, University of Turin, Turin, Italy \\ Email: lara.colombo@unito.it
}

Received 7 February 2014; revised 19 March 2014; accepted 1 April 2014

Copyright (C) 2014 by authors and Scientific Research Publishing Inc.

This work is licensed under the Creative Commons Attribution International License (CC BY). http://creativecommons.org/licenses/by/4.0/

(c) (i) Open Access

\begin{abstract}
Within the healthcare context is very important to foster the dynamics leading to positive experiences at work, in order to promote work motivation and well-being. This study investigated the influence of some personal and job resources and of some job demands on the three dimensions (absorption, work enjoyment, intrinsic work motivation) of flow at work, on the basis of Job Demands-Resources Model. Flow at work is an inner experience arising during an activity in which people are immersed, feel motivated and enjoy it. Studies suggest that resources are the main antecedents of the flow experience. Respondents to the questionnaire were 197 nurses. Multiple regressions were performed to detect the resources and the demands that influence the three dimensions of flow at work. As expected, resources positively influenced the dimensions of flow at work, particularly work enjoyment. Job demands positively influenced absorption and negatively influenced the other two dimensions of flow at work. Human resources managers should promote flow at work supporting the availability of resources and monitoring the job demands.
\end{abstract}

\section{Keywords}

Flow at Work; Work Motivation; Positive Psychology; Job Demands-Resources Model; Healthcare Context

\section{Introduction}

Most of studies in the healthcare context have particularly focused on the dynamics of distress and on the determinants of emotional exhaustion or job dissatisfaction [1]. Recently, some scholars [2] have highlighted the need to assume a more "positive" point of view in the analysis of work experiences, through the understanding 
of processes generating motivation and, consequently, experiences of well-being and job satisfaction. Organizational psychologists have long been interested in the job-related antecedents of work motivation [3], and the positive psychology perspective has given importance to the role of job resources in work motivation processes [4]. Within studies that investigate motivational dynamics, the flow at work $(\mathrm{FaW})$ experience is described as the most favourable circumstance for both the individual and the organizations, since flow is a state of consciousness in which people become totally immersed in an activity, and enjoy it intensely [5].

Studies on FaW are related to those organizational studies that detect the antecedents of work motivation [3]-[6], which can be defined as the energy that activates, leads and supports the behavior during the time and towards the achievement of a goal. In particular, work motivation implies a double investment for the individual: in the job performance and in the relationship of belonging to the organization [7]. Therefore, understanding the elements leading to the FaW experience is crucial in order to identify the factors supporting work motivation, that produces a benefit both for the organization in terms of results, and for the individuals in terms of satisfaction and well-being.

The purpose of this study is to examine the relation between personal and job resources and job demands, and the three dimensions of $\mathrm{FaW}$, in a sample of nurses, considering the theoretical framework of the Job DemandsResources Model (JD-R Model) [8]. This model was chosen since studies on FaW take place within the $J D-R$ Model [3] [9]-[11].

\subsection{Flow and Flow at Work}

According to Csikszentmihalyi [5] flow is a state of consciousness, an inner experience produced by the participation to an activity considered enjoyable and in which people are totally immersed. Flow is a peak experience that happens in any situation in which there is activity, "[...] when psychic energy—or attention—is invested in realistic goals, and when skills match the opportunities for action" (p. 6). This means that flow has two peculiarities: people enjoy the activity and invest time and energy in it; people experience flow when there is a balance between the challenge of a situation and their skills to deal with it.

The first studies detecting flow have focused on recreational or reflexive activities, and on sport [5]. Other researches [12] suggest that individuals experience flow more frequently during work than during leisure time. Applied to work, the flow experience can be defined as a short-term peak characterized by three dimensions: absorption, work enjoyment and intrinsic work motivation [10]. The first dimension, Absorption, is state of total concentration in which people are so immersed in their work that they forget everything around them and time passes rapidly. The dimension of Work Enjoyment refers to a state in which people like their job and feel positive emotions, judging positively the quality of their working life. This enjoyment is the outcome of cognitive and affective evaluations of the flow experience. The third dimension, named Intrinsic Work Motivation, refers to the performance of an activity during which people want to experience pleasure and satisfaction. The intrinsic motivation comes from the intrinsic aspect of the work and motivated employees are continuously interested in their work and want to continue it.

Referring to the flow theory, the FaW experience occurs when employees perceive a "challenge-skill balance"; this means that employees would particularly experience flow when their job demands match their professional skills [10] or when employees have sufficient amount of resources in their work, e.g. organizational support, performance feedback, good material, job autonomy, positive climate etc. [13].

\subsection{Flow at Work and the JD-R Model}

Studies on FaW mainly considered the theoretical framework of the JD-R Model that states that each type of job is characterized by risk and protective factors that impact on motivation and on the quality of working life. These factors are classified into two general categories: demands and resources. The $J D-R$ Model can be applied to different employments, independently from the demands and the resources involved [8]. Studies on the $J D-R$ Model provide information about the relations between the three dimensions of FaW and job demands and resources [10]: job demands requiring high concentration can lead to absorption and reduce work pleasure; resources are positively related to the three dimensions of FaW since they lead employees to motivation and to reach their goals at work. Demerouti [14] and Salanova et al. [11] suggest that job resources are the main antecedents of the flow experience. Bakker and Demerouti [8] define job resources as "those physical, psychological, social, or organizational aspects of the job that are either/or: functional in achieving work goals, reduce job de- 
mands and the associated physiological and psychological costs, stimulate personal growth, learning, and development”. Within job resources, authors mostly indicate: team climate, supervisor and co-worker support, feedback, career opportunities, job autonomy, etc.

Hypothesis 1. Job resources (job competencies, supervisors' support, job autonomy, organizational equity) are positively related to the three dimensions of FaW.

According to the Conservation of Resources (COR) theory [15] and also to the JD-R Model [8], the study of flow can involve not just job resources, but also the personal resources that can positively influence the optimal experience at work. Personal resources are defined as aspect of the self that are generally linked to resilience and a study by Salanova et al. [11] on the relationships between job resources, personal resources and FaW highlighted the role of self-efficacy in decreasing the effects of distress and in increasing well-being experiences.

Hypothesis 2. Personal resources (self-efficacy at work, optimism) are positively related to the three dimensions of FaW.

Bakker and Demerouti [8] define job demands as "those physical, psychological, social, or organizational aspects of the job that require sustained physical and/or psychological (cognitive and emotional) effort or skills and are therefore associated with certain physiological and/or psychological costs". Within job demands, authors mostly indicate: work pressure, unfavourable physical environment, emotionally demanding interactions with clients etc. The present study considered general demands (workload and cognitive load) and healthcare specific demands, such as patients' demands and emotional dissonance. Health professionals are engaged not only in providing a professional service to users, but also in managing the emotional experiences connected to the relationships with patients and their families. In line with Bakker's study [10], it is expected that all resources (personal and job), as already highlighted, have a positive influence on the three dimensions of FaW, since resources start a motivational process [16]. Contrary, again in line with Bakker's study, it is expected that job demands have both negative and positive influences on the dimensions of FaW. This is because demands and efforts make people more concentrated and, therefore, absorbed [10]. Moreover, high work pressure and emotionally demanding patients will presumably undermine work pleasure [17].

Hypothesis 3a. Job demands (workload, cognitive load, patients' demands, emotional dissonance) are negatively related to work enjoyment and intrinsic work motivation.

Hypothesis 3b. Job demands (workload, cognitive load, patients' demands, emotional dissonance) are positively related to absorption.

Finally, in line with studies on FaW that consider the motivational potential of resources [9] [11] [14], the following hypothesis is formulated:

Hypothesis 4. The relation between personal resources and the three dimensions of FaW, and the relation between job resources and the three dimensions of $\mathrm{FaW}$ are higher than the relation between job demands and the three dimensions of FaW.

\section{Methods}

\subsection{Subjects}

After data cleansing, through which 52 incomplete questionnaires were eliminated, the convenience sample (Table 1) was composed of 197 permanent nurses employed in some departments of a hospital in Northern Italy. Respondents represented about $60 \%$ of subjects who received the questionnaire, and the social and personal characteristics were similar to the population of the departments involved in the administration. The majority of respondents were women, and this is in line with data from CENSIS (Centro Studi Investimenti Sociali-Italian institute on socio-economic research) [18]. The average age of the sample was about 42 years (SD 8.37) and the seniority in the organization was about 15 years (SD 9.61). Most of respondents were married or live-in partner, had children and worked on shifts. From a workload standpoint, respondents worked about 36 hours per week (SD 5.94).

\subsection{Study Questionnaire}

The present research has provided a self-report questionnaire consisting of a socio-demographic form and different scales chosen from the existing international literature. The instrument was composed of the following scales, some of which were previously used in other Italian researches: 
Table 1. Socio-demographic and professional characteristics of the sample $(\mathrm{N}=197)$.

\begin{tabular}{|c|c|c|c|}
\hline & & $\mathrm{N}$ & $\%$ \\
\hline \multirow{2}{*}{ Gender } & Woman & 184 & 93.4 \\
\hline & Man & 13 & 6.6 \\
\hline \multirow{3}{*}{$\begin{array}{c}\text { Household } \\
\text { characteristics }\end{array}$} & Single or with original Household & 40 & 20.3 \\
\hline & Married or in Cohabitation & 129 & 65.5 \\
\hline & Divorced, separated or widow & 28 & 14.2 \\
\hline \multirow{2}{*}{ Children } & Yes & 134 & 68 \\
\hline & No & 63 & 32 \\
\hline \multirow{2}{*}{ Job tenure } & Full-time & 161 & 81.7 \\
\hline & Part-time & 36 & 18.3 \\
\hline \multirow{2}{*}{ Work shifts } & Yes (nurses working on 24 hours shifts: morning, afternoon, night) & 75 & 38.1 \\
\hline & No (nurses working on one day shift) & 122 & 61.9 \\
\hline
\end{tabular}

- FaW-13-item Likert scale from 1 (never) to 7 (always) of the WOLF scale (WOrk-reLated Flow) by Bakker [10], Italian adaptation by Colombo, Zito, Cortese [19]. The scale is composed by three dimensions: $a b-$ sorption (4 items. In this study $\alpha 0.87$; in the original study $\alpha$ around 0.80 ; in the Italian adaptation $\alpha 0.90$ ); work enjoyment (4 items. In this study $\alpha 0.94$; in the original study $\alpha$ around 0.80 ; in the Italian adaptation $\alpha$ 0.95 ); intrinsic work motivation (5 items. In this study $\alpha 0.78$; in the original study $\alpha$ around 0.75 ; in the Italian adaptation $\alpha 0.84$ ).

- Optimism -6-item Likert scale from 1 (disagree) to 5 (agree) [20]. In this study $\alpha 0.70$; in the original study $\alpha 0.75$.

- Self-efficacy at work-5-item Likert subscale of the WSES (Work Self-Efficacy Scale) by Avallone, Pepe, and Porcelli [21], from 1 (not at all capable) to 5 (quite capable). In this study $\alpha 0.80$; in the original study $\alpha$ 0.83 .

- Job competencies-7-item Likert scale from 1 (never) to 4 (always) of the diagnostic functions subscale of the NCS (Nurse Competence Scale) by Meretoja, Isoaho, and Leino-Kilpi [22]. This subscale was used in previous Italian studies [23] with a $\alpha 0.85$; in this study $\alpha 0.85$, in the original study $\alpha 0.79$.

- Supervisors' support-4-item Likert scale from 1 (not at all) to 6 (completely) of the subscale of organizational support by Caplan, Cobb, French, Harrison, and Pinneau [24]. This subscale was used in Colombo and Zito [23] with a $\alpha 0.88$; in this study $\alpha 0.87$, in the original study $\alpha 0.94$.

- Job autonomy -3-item Likert scale from 1 (never) to 5 (always) by Bakker, Demerouti, and Verbeke [25]. This scale was used in Colombo and Zito [23] with a $\alpha 0.75$; in this study $\alpha 0.70$; in the original study $\alpha 0.81$.

- Organizational equity -4-item Likert scale from 1 (never) to 4 (always) by Avallone and Paplomatas [26]. In this study $\alpha 0.81$, in the original study $\alpha 0.76$.

- Workload -6-item Likert scale from 1 (disagree) to 6 (agree) by Karasek and Theorell [27]. This scale was used in Colombo and Zito [23] with a $\alpha$ 0.91; in this study $\alpha$ 0.92; in the original study $\alpha 0.80$.

- Cognitive load - 4-item Likert scale from 1 (never) to 5 (always) by Bakker, Demerouti, Taris, Schaufeli and Schreurs [28]. In this study $\alpha 0.87$; in the original study $\alpha 0.81$.

- Patients' demands-11-item Likert scale from 1 (disagree) to 6 (agree) of the disproportionate customer expectations subscale of the CSS questionnaire by Dorman and Zapf [29]. In this study $\alpha 0.91$; in the original study $\alpha$ 0.85. The items were adapted for the healthcare context and already used in Colombo and Zito [23] with a $\alpha 0.92$.

- Emotional dissonance-4-item Likert scale from 1 (never) to 6 (always) by Zapf, Vogt, Seifert, Mertini, and Isic [30]. This scale was used in Colombo and Zito [23] with a $\alpha 0.90$; in this study $\alpha 0.90$; in the original study $\alpha 0.85$.

\subsection{Ethical Considerations}

The study was approved by the Board of Directors of the hospital. After the management permission, researchers delivered the questionnaire to nursing coordinators of the involved departments, who, in turn, distributed 
them to nurses. Moreover, researchers attached a covering letter to the questionnaire to explain the procedure and time to complete the questionnaire (about 30 minutes estimated through a questionnaire pre-test), the voluntary nature of the participation in the study and all respondents' anonymity. In order to ensure this aspect, respondents did not return their completed questionnaire to their nursing coordinators, but in drop boxes in which they could personally deposit their completed questionnaire.

\subsection{Data Analysis}

Data analysis were performed using SPSS Statistics 20 and provided: descriptive statistics (mean \pm SD) and Cronbach's alphas $(\alpha)$ for each scale; correlations (Pearson's $r$ ), multiple regressions (method: enter), including the three dimensions of FaW as dependent variables. Finally, to understand differences in the perception of the dimensions of FaW according to the main socio-demographic and professional variables, it was performed the analysis of variance through T-test for independent samples and one way Anova.

\section{Results}

All the scales used in the present study showed a good internal consistency: the Cronbach's alpha values ranged between 0.70 and 0.94 (Table 2), and, compared with the values of the original studies, the Cronbach's alphas in this study are satisfactory. As for the descriptive statistics of the three dimensions of FaW (Table 2), respondents perceive a higher level of absorption (above the central point of the scale; $4.41 \pm 1.31$ ) and of work enjoyment (almost at the central point of the scale; $4.07 \pm 1.35$ ), and a lower level of intrinsic work motivation (below the central point of the scale; $3.37 \pm 0.54$ ). The analysis of variance found no statistically significant differences in the scores of the three dimensions of FaW depending on socio-demographic and professional variables.

Table 2 shows the correlations between the variables. In line with Bakker's study [10] on the validation of the WOLF scale, the dimensions of work enjoyment and intrinsic work motivation are highly correlated. As expected, personal and job resources positively correlate with the three dimensions of FaW, particularly with work enjoyment and intrinsic work motivation. As for job demands, workload positively correlates with absorption. Patients' demands and emotional dissonance instead, negatively correlate with work enjoyment and intrinsic work motivation. The cognitive load does not present significant correlations with any of the three dimensions of FaW. The three dimensions of FaW show the expected correlations with the variables used in the research, showing a construct validity in line with Bakker's study [10]. Within the socio-demographic and professional variables, only the seniority in the organization shows a positive relation, but not particularly high, with the absorption. Table 3 shows the results of multiple regressions for the three dimensions of FaW. It has to be noted that only the variables that correlated with the dependent variables were included in the regression models. Work enjoyment (explained variance $46 \%$ ) is positively influenced by optimism $(\beta=0.25, \mathrm{p}<0.00$ ) and by job competencies $(\beta=0.24, \mathrm{p}<0.00)$, by organizational equity $(\beta=0.16, \mathrm{p}<0.05)$ and less by job autonomy $(\beta=$ $0.11, \mathrm{p}<0.00)$. Conversely, work enjoyment is negatively influenced by patients' demands $(\beta=-0.16, \mathrm{p}<0.05)$ and emotional dissonance $(\beta=-0.14, \mathrm{p}<0.05)$. As work enjoyment, intrinsic work motivation (explained variance 29\%) is positively influenced by optimism ( $\beta=0.19$, $\mathrm{p}<0.00)$, job competencies $(\beta=0.19, \mathrm{p}<0.00)$ and by job autonomy $(\beta=0.17, \mathrm{p}<0.05)$, and it is negatively influenced by emotional dissonance $(\beta=-0.16, \mathrm{p}<$ 0.05 ). Absorption (explained variance $20 \%$ ) is increased by job competencies $(\beta=0.25, \mathrm{p}<0.00$ ), by workload $(\beta=0.22, \mathrm{p}<0.00)$ and less by job autonomy $(\beta=0.15, \mathrm{p}<0.05)$.

\section{Discussion}

The aim of the present study was to investigate the influence of personal and job resources and of job demands on the three dimensions of FaW (absorption, work enjoyment and intrinsic work motivation), in a sample of Italian nurses. Studies detecting FaW in the Italian health care context are scant. More specifically, there are no studies that investigate the flow experience among nurses, except for the study by Bringsén et al. [1] and by Colombo and Zito [23].

As shown by descriptive statistics, respondents perceive a higher level of absorption, suggesting the demanding characteristics of their job. However, work enjoyment and intrinsic work motivation have acceptable scores, particularly work enjoyment, indicating also pleasure at work. The lack of statistical significant differences in 
Table 2. Correlations (r Pearson) between variables, descriptive statistics (mean, and standard deviation) and reliabilities (N =197).

\begin{tabular}{|c|c|c|c|c|c|c|c|c|c|c|c|c|c|c|c|c|c|c|c|}
\hline & 1 & 2 & 3 & 4 & 5 & 6 & 7 & 8 & 9 & 10 & 11 & 12 & 13 & 14 & 15 & 16 & 17 & 18 & 19 \\
\hline 1. Absorption & $(0.87)$ & & & & & & & & & & & & & & & & & & \\
\hline $\begin{array}{l}\text { 2. Work } \\
\text { enjoyment }\end{array}$ & $0.44^{* *}$ & $(0.94)$ & & & & & & & & & & & & & & & & & \\
\hline $\begin{array}{l}\text { 3. Intrinsic work } \\
\text { motivation }\end{array}$ & $0.49^{* *}$ & $0.71^{* *}$ & $(0.78)$ & & & & & & & & & & & & & & & & \\
\hline $\begin{array}{l}\text { 4. Gender } \\
\text { (1 = female) }\end{array}$ & -0.04 & -0.04 & 0.00 & - & & & & & & & & & & & & & & & \\
\hline $\begin{array}{l}\text { 5. Job tenure } \\
\text { (1 = full time) }\end{array}$ & 0.01 & -0.01 & -0.04 & -0.13 & - & & & & & & & & & & & & & & \\
\hline $\begin{array}{l}\text { 6. Work shifts } \\
(1=\text { shifts })\end{array}$ & -0.12 & -0.04 & -0.03 & -0.04 & 0.03 & - & & & & & & & & & & & & & \\
\hline 7. Age & 0.10 & -0.01 & -0.08 & 0.07 & -0.12 & $-0.26^{* *}$ & - & & & & & & & & & & & & \\
\hline $\begin{array}{l}\text { 8. Seniority in } \\
\text { the organization }\end{array}$ & $0.14^{*}$ & -0.00 & 0.03 & 0.13 & $-0.17^{*}$ & $-0.31^{* *}$ & $0.72^{* *}$ & - & & & & & & & & & & & \\
\hline $\begin{array}{l}\text { 9. Weekly } \\
\text { working hours }\end{array}$ & 0.01 & -0.11 & -0.06 & -0.04 & $0.62^{* *}$ & $0.19^{* *}$ & -0.02 & -0.02 & - & & & & & & & & & & \\
\hline 10. Optimism & $0.15^{*}$ & $0.41^{* *}$ & $0.33^{* *}$ & -0.04 & 0.07 & 0.01 & -0.06 & 0.02 & 0.01 & $(0.70)$ & & & & & & & & & \\
\hline $\begin{array}{l}11 \text {. Self-efficacy } \\
\text { at work }\end{array}$ & $0.18^{* *}$ & $0.22^{* *}$ & $0.20^{* *}$ & 0.01 & $0.16^{*}$ & 0.08 & -0.01 & -0.06 & 0.09 & $0.26^{* *}$ & $(0.80)$ & & & & & & & & \\
\hline $\begin{array}{l}\text { 12. Job } \\
\text { competencies }\end{array}$ & $0.32^{* *}$ & $0.41^{* *}$ & $0.33^{* *}$ & 0.03 & 0.11 & -0.08 & 0.07 & 0.07 & 0.06 & $0.22^{* *}$ & $0.31^{* *}$ & $(0.85)$ & & & & & & & \\
\hline $\begin{array}{l}\text { 13. Supervisors' } \\
\text { support }\end{array}$ & $0.17^{*}$ & $0.31^{* *}$ & $0.26^{* *}$ & 0.02 & -0.12 & -0.09 & -0.05 & 0.04 & -0.13 & 0.05 & -0.10 & 0.07 & $(0.87)$ & & & & & & \\
\hline $\begin{array}{l}\text { 14. Job } \\
\text { autonomy }\end{array}$ & $0.29^{* *}$ & $0.38^{* *}$ & $0.35^{* *}$ & -0.07 & -0.03 & -0.09 & -0.07 & 0.04 & -0.06 & 0.11 & $0.22^{* *}$ & $0.18^{*}$ & $0.30^{* *}$ & $(0.70)$ & & & & & \\
\hline $\begin{array}{l}\text { 15. Organizational } \\
\text { equity }\end{array}$ & $0.21^{* *}$ & $0.39^{* *}$ & $0.31^{* *}$ & 0.14 & -0.02 & $-0.15^{*}$ & 0.10 & 0.13 & -0.03 & $0.16^{*}$ & -0.05 & $0.17^{*}$ & $0.46^{* *}$ & $0.28^{* *}$ & $(0.81)$ & & & & \\
\hline 16. Workload & $0.20^{* *}$ & -0.05 & 0.01 & -0.04 & -0.00 & $0.17^{*}$ & -0.09 & -0.09 & $0.16^{*}$ & 0.07 & $0.18^{* *}$ & -0.01 & -0.07 & 0.06 & -0.13 & $(0.92)$ & & & \\
\hline $\begin{array}{l}\text { 17. Cognitive } \\
\text { load }\end{array}$ & 0.12 & -0.07 & -0.05 & -0.10 & 0.03 & $0.22^{* *}$ & $-0.21^{* *}$ & $-0.16^{*}$ & $0.18^{*}$ & 0.07 & 0.14 & 0.13 & -0.02 & 0.09 & $-0.16^{*}$ & $0.56^{* *}$ & $(0.87)$ & & \\
\hline $\begin{array}{l}\text { 18. Patients' } \\
\text { demands }\end{array}$ & -0.07 & $-0.34^{* *}$ & $-0.21^{* *}$ & 0.08 & 0.09 & 0.14 & 0.00 & -0.05 & 0.07 & -0.10 & $0.16^{*}$ & -0.13 & $-0.26^{* *}$ & -0.10 & $-0.22^{* *}$ & ${ }^{*} 0.29^{* *}$ & $0.19^{* *}$ & $*(0.91)$ & \\
\hline $\begin{array}{l}\text { 19. Emotional } \\
\text { dissonance }\end{array}$ & -0.04 & $-0.37^{* *}$ & $-0.29^{* *}$ & 0.06 & 0.04 & 0.07 & 0.05 & -0.04 & 0.09 & -0.13 & 0.01 & -0.03 & $-0.19^{* *}$ & $-0.22^{* *}$ & $* 0.23^{* *}$ & ${ }^{*} 0.27^{* *}$ & $0.21^{* *}$ & ${ }^{*} 0.40^{* *}$ & * $(0.90)$ \\
\hline M & 4.41 & 4.07 & 3.37 & - & - & - & 42.07 & 15.54 & 35.78 & 3.89 & 4.39 & 2.93 & 3.82 & 3.51 & 2.02 & 4.38 & 4.32 & 4.29 & 3.59 \\
\hline SD & 1.31 & 1.35 & 0.54 & - & - & - & 8.37 & 9.61 & 5.94 & 0.51 & 0.47 & 0.52 & 1.34 & 0.82 & 0.67 & 1.09 & 0.64 & 1.03 & 1.25 \\
\hline
\end{tabular}

Note. ${ }^{*} \mathrm{p}<0.05 ;{ }^{* *} \mathrm{p}<0.01 ; \mathrm{M}=$ mean (for the scales it is shown the scale mean); SD = standard deviation; Cronbach's alpha's on the diagonal between brackets.

FaW scores, may suggest that this experience is more linked to the working environment and thus to the available resources; this evidence is confirmed also by the absence of statistical significant correlations between socio-demographic and professional variables and the three dimensions of FaW.

Despite the high correlation between work enjoyment and intrinsic work motivation, these two dimensions show relations partly different with the variables included in the research design, supporting the theoretical and methodological choice to keep separate the two dimensions of FaW.

As for job resources, not all the variables show a relationship with the dependent variable, thus partially confirming Hp1. The variable that most positively influences the three dimensions of FaW is referred to the possession of professional skills (job competencies). This result is in line with the theoretical assumption that characterizes the balance between challenges and skills: the perception of being able to cope the work challenges with the own skills and competencies is a basic requisite to the achievement of the FaW experiences. In addition to 
Table 3. Multiple regressions (method: enter; standardized coefficients)—dependent variables: absorption, work enjoyment, intrinsic work motivation.

\begin{tabular}{|c|c|c|c|c|c|c|c|c|c|}
\hline & \multicolumn{3}{|c|}{ Absorption } & \multicolumn{3}{|c|}{ Work enjoyment } & \multicolumn{3}{|c|}{ Intrinsic work motivation } \\
\hline & $\beta$ & $t$ & $p$ & $\beta$ & $t$ & $p$ & $\beta$ & $t$ & $p$ \\
\hline Seniority in the organization & 0.13 & 1.93 & 0.06 & - & - & - & - & - & - \\
\hline Optimism & 0.03 & 0.40 & 0.69 & 0.25 & 4.50 & 0.00 & 0.19 & 3.05 & 0.00 \\
\hline Self-efficacy at work & 0.04 & 0.58 & 0.56 & 0.09 & 1.44 & 0.15 & 0.08 & 1.16 & 0.25 \\
\hline Job competencies & 0.25 & 3.54 & 0.00 & 0.24 & 4.13 & 0.00 & 0.19 & 2.94 & $\mathbf{0 . 0 0}$ \\
\hline Supervisors' support & 0.07 & 0.92 & 0.36 & 0.10 & 1.59 & 0.11 & 0.10 & 1.45 & 0.15 \\
\hline Job autonomy & 0.15 & 2.15 & 0.03 & 0.11 & 2.81 & 0.00 & 0.17 & 2.59 & 0.01 \\
\hline Organizational equity & 0.11 & 1.40 & 0.16 & 0.16 & 2.53 & 0.01 & 0.11 & 1.55 & 0.12 \\
\hline Patients' demands & - & - & - & -0.16 & -2.67 & 0.01 & -0.05 & -0.73 & 0.47 \\
\hline Emotional dissonance & - & - & - & -0.14 & -2.39 & 0.02 & -0.16 & -2.36 & 0.02 \\
\hline Workload & 0.22 & 3.30 & 0.00 & - & - & - & - & - & - \\
\hline$R^{2}$ & & 0.20 & & & 0.46 & & & 0.29 & \\
\hline
\end{tabular}

the competencies, also job autonomy, even if less, positively acts in increasing the three dimensions of FaW. Also this result is in line with literature and particularly with Csikszentmihalyi's studies [5] that highlight the importance of control and discretion in performing the work activity. The organizational equity, intended as the perception of recognition of work effort and of professional development opportunities, is a job resource that can positively influence, in this study, only on the dimension of work enjoyment.

Within personal resources, only optimism shows a positive impact on the two dimensions of FaW, work enjoyment and intrinsic work motivation, highlighting the individual disposition to be positive to reach optimal experiences at work. Therefore, Hp2 is partially confirmed.

As for job demands, Hp3a and Hp3b are also partially confirmed: work enjoyment and intrinsic work motivation are reduced by emotional dissonance, whereas patients' demands reduce only work enjoyment. Workload, increases absorption, in line with literature [10].

Finally, Hp4 is confirmed: the influence of personal resources and of job resources on the dimensions of FaW is higher than the influence of job demands, in line with the studies that indicate resources as the main antecedent of flow [9] [11] [14].

\section{Implications for Nursing Management}

For organizations, and specifically for those who manage human resources, it may be very useful to understand and to foster the dynamics that lead to positive experience at work. Researches on Positive Organizational Behavior should provide useful indications for a "positively" oriented management of the human resources and thus, designed to the development of job performance [31] and to the promotion of employees' motivation. Referring to motivation, it is therefore interesting to analyse the determinants of the flow experience which, in turn, can positively influence well-being and job performance [14], through the achievement of a balance between challenges and skills that makes individuals aware of their own goals and of the possibility to reach them: aware employees that improve their performance represent a great resource for organizations in terms of productivity.

Promoting FaW is possible by increasing the resources in the organization [14]-[32] since they are potentially motivating by giving meaning to the work, make employees feel responsible for the work processes and the achieved results, and provide information about the real results [3]. The findings of the present research support the role of resources, particularly of job resources, in increasing FaW experiences. In particular, to increase the experience of work enjoyment and of intrinsic work motivation is necessary to enhance the professional competencies, the job autonomy and, particularly for work enjoyment, the organizational equity. In contrast, negative experiences linked to the relationship with patients represent a threat to the achievement of flow experiences, especially those related to work enjoyment and to intrinsic work motivation. As expected, workload increases absorption, highlighting that it is work pressure, and not so much the relation with patients and the emotional 
dissonance, that generates concentration and absorption.

More specifically, the practical implications for the management to promote FaW among nurses, emerging from the present research, are oriented towards three principal intervention areas.

The first area refers to the professional aspects to allow nurses to develop, through training, professional competencies and cross competencies (communication techniques, teamwork, empowerment etc.). In fact, job competencies are considered as resources, and referring to the literature, resources can foster the flow experience.

The second intervention area refers to nurses' psychological support, through individual or in team counselling, to sustain them in the management of the emotional demands. These demands, on the basis of the present study, seem to undermine the intrinsic work motivation and the work enjoyment. Psychological counselling, moreover, can empower personal resources and increase positive and motivational experiences at work.

The last intervention area refers to nursing coordinators. In particular, it is necessary to sensitize them, through specific training, about the importance of creating a work climate that can activate flow experiences. This is possible through daily feedback, by giving professional and emotional support, by giving clear working tasks, and by monitoring the employees' competencies in order to offer them adequate working challenges. More specifically, findings suggest to guarantee job autonomy that increases each of the flow dimensions. Job autonomy is based on the reciprocal trust between supervisor and employee: the supervisor should make the employee feel free and autonomous, ensuring constructive feedback and organizational equity (that increases, in particular, work enjoyment). Moreover, nursing coordinator should monitor also the workload: it is important to limit or to distribute more effectively the workload among the nursing staff, since this load can lead to an excessive absorption and attentional engagement.

\section{Conclusion}

In general, promoting a "positive" organizational culture, nurtured by flow experiences, represents a relevant organizational goal. Fostering FaW, in fact, is not just functional to a better performance and productivity, but is essential to prevent the risk of exhaustion at work [32], to protect health and, in general, the employees' quality of working life.

\section{Limitations of the Study}

The limitations of the present study are first due to the low number of participants in the research and the involvement of only one organizational context; the results, therefore, are not generalizable to other hospitals. Another limitation refers to the use of a self-report questionnaire and of a cross-section research design that not permit to establish sure relations of causality between the variables. In this regard, future studies could include longitudinal researches and an expansion of the sample through the involvement of other hospital contexts, also to evaluate possible differences between organizations. Furthermore, since common method variance may have been responsible of part of the results, it is desirable that future research use different sources of information as other-ratings of working conditions in addition to self-reports of flow. Finally, this research, as other studies on this topic, detects FaW retrospectively. This procedure does not permit to measure real-time flow, and this makes difficult to map the precise prevalence of peak experience, as Csikszentmihalyi's [5] ESM procedure does. However, it has to be noted that for the construction of the WOLF scale by Bakker and other studies on $\mathrm{FaW}$, questionnaires were used with good results.

The present research examined each of the three dimensions of FaW separately. The reason is that distinct relationships with other variables are most informative to comprise the construct of FaW, and, therefore, to act on variables influencing the three dimensions of FaW.

Future research could combine the three dimensions of FaW into one overall flow score, as in other studies by Bakker [9] and by Salanova et al. [11] that treated the three dimensions of FaW as indicators of a latent flow variable. Another point to deepen is the role of supervisors' support in the FaW dynamics: in the regression model of the present study, this variable is not related with the dimensions of FaW. It could therefore be hypothesized a role of moderator of supervisors' support between job demands and resources. Moreover, it should be interesting to explore with structural equation models the effect of demands and resources on FaW and on outcome variables, both positive (well-being) and negative (distress) and the impact of $\mathrm{FaW}$ on these outcomes. 


\section{References}

[1] Bringsén, A., Ejlertsson, G. and Andersson, I.H. (2011) Flow Situations during Ever Day Practice in a Medical Hospital Ward. Results from a Study Based on Experience Sampling Method. BMC Nursing, 10, 1-9. http://dx.doi.org/10.1186/1472-6955-10-3

[2] Kelloway, K.E., Teed, M. and Kelley, E. (2008) The Psychosocial Environment: Towards an Agenda for Research. International Journal of Workplace Health Management, 1, 50-64.

[3] Mäkikangas, A., Bakker, A.B., Aunola, K. and Demerouti, E. (2010) Job Resources and Flow at Work: Modelling the Relationship via Latent Growth Curve and Mixture Model Methodology. Journal of Occupational and Organizational Psychology, 3, 795-814. http://dx.doi.org/10.1348/096317909X476333

[4] Bakker, A.B. and Demerouti, E. (2008) The Crossover of Work Engagement: A Closer Look at the Role of Empathy. Special Issue on Crossover for Journal of Managerial Psychology, 1-29.

[5] Csikszentmihalyi, M. (1990) Flow. The Psychology of Optimal Experience. Harper and Row, New York.

[6] Hackman, J.R. and Oldham, G.R. (1980) Work Redesign. Addison-Wesley, Reading.

[7] Cortese, C.G. (2005) Motivare. Raffaello Cortina, Milano.

[8] Bakker, A.B. and Demerouti, E. (2007) The Job Demands-Resources Model: State of the Art. Journal of Managerial Psychology, 22, 309-328. http://dx.doi.org/10.1108/02683940710733115

[9] Bakker, A.B. (2005) Flow among Music Teachers and Their Students: The Crossover of Peak Experiences. Journal of Vocational Behavior, 66, 26-44. http://dx.doi.org/10.1016/j.jvb.2003.11.001

[10] Bakker, A.B. (2008) The Work-Related Flow Inventory: Construction and Initial Validation of the WOLF. Journal of Vocational Behavior, 72, 400-414. http://dx.doi.org/10.1016/j.jvb.2007.11.007

[11] Salanova, M., Bakker, A.B. and Llorens, S. (2006) Flow at Work: Evidence for an Upward Spiral of Personal and Organizational Resources. Journal of Happiness Studies, 7, 1-22. http://dx.doi.org/10.1007/s10902-005-8854-8

[12] Csikszentmihalyi, M. and LeFevre, J. (1989) Optimal Experience in Work and Leisure. Journal of Personality and Social Psychology, 5, 815-822. http://dx.doi.org/10.1037/0022-3514.56.5.815

[13] Csikszentmihalyi, M. (2003) Good Business. Leadership, Flow and Making the Meaning. Penguin Group, New York.

[14] Demerouti, E. (2006) Job Characteristics, Flow, and Performance: The Moderating Role of Conscientiousness. Journal of Occupational Health Psychology, 11, 266-280. http://dx.doi.org/10.1037/1076-8998.11.3.266

[15] Hobfoll, S.E. (2002) Social and Psychological Resources and Adaptation. Review of General Psychology, 6, $307-324$. http://dx.doi.org/10.1037/1089-2680.6.4.307

[16] Bakker, A.B., Demerouti, E., De Boer, E. and Schaufeli, W.B. (2003) Job Demands and Job Resources as Predictors of Absence Duration and Frequency. Journal of Vocational Behavior, 62, 341-356. http://dx.doi.org/10.1016/S0001-8791(02)00030-1

[17] Demerouti, E., Bakker, A.B., Nachreiner, F. and Schaufeli, W.B. (2000) A Model of Burnout and Life Satisfaction among Nurses. Journal of Advanced Nursing, 32, 454-464. http://dx.doi.org/10.1046/j.1365-2648.2000.01496.x

[18] CENSIS (2012) L’infermiere protagonista della buona sanità del futuro. http://www.censis.it

[19] Colombo, L., Zito, M. and Cortese, C.G. (2013) The Italian Version of the Work-Related Flow Inventory (WOLF): First Psychometric Evaluations. Bollettino di Psicologia Applicata, 268, 37-42.

[20] Scheier, M.F., Carver, C.S. and Bridges, M.W. (1994) Distinguishing Optimism from Neuroticism (and Trait Anxiety, Self-Mastery, and Self-Esteem): A Reevaluation of the Life Orientation Test. Journal of Personality and Social Psychology, 67, 1063-1078. http://dx.doi.org/10.1037/0022-3514.67.6.1063

[21] Avallone, F., Pepe, S. and Porcelli, R. (2007) Autoefficacia percepita nella ricerca del lavoro: Scale di misura. In: Isfol, Bisogni, valori e autoefficacia nella scelta del lavoro, ISFOL, Roma, 133-142.

[22] Meretoja, R., Isoaho, H. and Leino-Kilpi, H. (2004) Nurse Competence Scale: Development and Psychometric Testing. Journal of Advanced Nursing, 47, 124-133. http://dx.doi.org/10.1111/j.1365-2648.2004.03071.x

[23] Colombo, L. and Zito, M. (2012) Job-Demands Resources Model and Exhaustion: The Role of Flow-Work Enjoyment. A Study in a Health Care Context. In: Mokryš, M. and Lieskovský, A., Eds., Advanced Research in Scientific Areas, EDIS-Published Institution of the University of Zilina, Zilina, 776-781.

[24] Caplan, R.D., Cobb, S., French Jr., J.R.P., Harrison, R.V. and Pinneau Jr., S.R. (1975) Job Demands Worker Health: Main Effects and Occupational Differences. National Institute of Occupational Safety and Health, US Government Printing Office, Washington DC.

[25] Bakker, A.B., Demerouti, E. and Verbeke, W. (2004) Using the Job Demands-Resources Model to Predict Burnout and Performance. Human Resource Management, 43, 83-104. http://dx.doi.org/10.1002/hrm.20004 
[26] Avallone, F. and Paplomatas, A. (2005) Salute Organizzativa. Raffaello Cortina, Milano.

[27] Karasek, R. and Theorell, T. (1990) Healthy Work-Stress, Productivity and the Reconstruction of Working Life. Basic Books, New York.

[28] Bakker, A.B., Demerouti, E., Taris, T., Schaufeli, W.B. and Schreurs, P. (2003) A Multi-Group Analysis of the Job Demands-Resources Model in Four Home Care Organizations. International Journal of Stress Management, 10, $16-38$. http://dx.doi.org/10.1037/1072-5245.10.1.16

[29] Dormann, C. and Zapf, D. (2004) Customer-Related Social Stressors and Burnout. Journal of Occupational Health Psychology, 9, 61-82. http://dx.doi.org/10.1037/1076-8998.9.1.61

[30] Zapf, D., Vogt, C., Seifert, C., Mertini, H. and Isic, A. (1999) Emotion Work as a Source of Stress: The Concept and the Development of an Instrument. European Journal of Work and Organizational Psychology, 8, 371-400. http://dx.doi.org/10.1080/135943299398230

[31] Luthans, F. (2003) Positive Organizational Behavior (POB): Implications for Leadership and HR Development and Motivation. In: Steers, R.M., Porter, L.W. and Bigley, G.A., Eds., Motivation and Leadership at Work, McGraw-Hill/ Irwin, New York.

[32] Demerouti, E., Bakker, A.B., Sonnentag, S. and Fullgar, C.J. (2012) Work-Related Flow and Energy at Work and at Home: A Study on the Role Daily Recovery. Journal of Organizational Behavior, 3, 276-295. http://dx.doi.org/10.1002/job.760 